\title{
Levels of Organochlorine in Cowpea from South-West Nigeria using Gas Chromatography-Mass Spectroscopy
}

\author{
Emmanuel Eimiomodebheki Odion ${ }^{1 *}$, Joel Okhumen Abolagba ${ }^{2}$, John Oamen Igene ${ }^{3}$, Stella Folajole \\ Usifoh $^{4}$, Caroline Edijana Omoti ${ }^{5}$, Cyril Odianose Usifoh ${ }^{1}$ \\ ${ }^{1}$ Department of Pharmaceutical Chemistry, University of Benin, Nigeria \\ ${ }^{2}$ Department of Aquaculture and Fisheries Management, University of Benin, Nigeria \\ ${ }^{3}$ Department of Food Science Technology, University of Benin, Nigeria \\ ${ }^{4}$ Department of Clinical Pharmacy and Pharmacy Practice, University of Benin, Nigeria \\ ${ }^{5}$ Department of Haematology, University of Benin, Nigeria
}

\section{*Corresponding Author}

Emmanuel Eimiomodebheki Odion

\section{Article History}

Received: 13.06 .2020

Accepted: 20.06 .2020

Published: 30.06 .2020

\begin{abstract}
The use of dichloro-diphenyl-trichloro-ethane and gamma-lindane has been limited in many countries but allowed to be used restrictively as prescription medicine in humans. However, in some developing countries, they are unscrupulously used in grains preservation. This study aimed at determining the concentration of DDT and $\gamma$-HCH in cowpeas collected from South-West states of Nigeria and determine the possible daily intake in these areas. Seventy-six samples of cowpeas were obtained from local markets in South-West Nigeria. Ten gramme of cowpea was weighed, pulverised, extracted with dichloromethane $(150 \mathrm{ml})$ and cleaned-up using silica gel. The extracts were then analysed for DDT and $\gamma$-HCH using GC-MS with a Restek column. The mean concentration of $\gamma-\mathrm{HCH}$ was highest in Agege market $(168.00 \pm 0.114) \mu \mathrm{g} / \mathrm{kg}$ in Lagos state, while Eleyele market $(64.26 \pm 0.138) \mu \mathrm{g} / \mathrm{kg}$ in Oyo state had the highest mean concentration of DDT. Health index of 6.13 was obtained for $\gamma-\mathrm{HCH}$ in children. This study has shown that high level of DDT and $\gamma-\mathrm{HCH}$ were used in the preservation of cowpeas. The concentration of these pesticides exceeded the maximum residual limit (MRL), making the cowpeas probably unfit for human consumption.
\end{abstract}

Keywords: Cowpea, DDT, Gamma lindane, Gas Chromatography-Mass Spectroscopy, Organochlorine, Restek column.

\section{Highlights}

- Organochlorine pesticide at high concentration are still been used in cowpea preservation in South-Western states of Nigeria.

- Health index of 6.13 was obtained for $\gamma-\mathrm{HCH}$ in children, probably making it unfit for consumption.

- The concentration of these pesticides exceeded the maximum residual limit (MRL) set by the European Union, which could probably be responsible for incidence of food poison.

\section{INTRODUCTION}

Dichloro-diphenyl-trichloro-ethane (DDT) and gamma-lindane an organochlorine pesticides (OCPs) with five to six chlorine atoms in the molecule. DDT is classified as a contact poison, that is applied on crops and seeds by spraying its aqueous suspension or its dust [1], that exerts its effect by disorganizing the nervous system [2]. Its metabolite 1,1dichloro-2,2-bis-(p-chlorophenyl)-ethylene (p,p'-DDE) inhibits the activity of androgen hormone and its receptor [3]. Intake of high quantity of DDT within a short time could lead to central nervous system effects and gastrointestinal disturbance $[4,5]$. Gamma lindane $(\gamma-\mathrm{HCH})$ is one of the isomers of hexachlorocyclohexane [6], with a strong insecticidal activity in agriculture and public health against external parasites [7]. Intake of toxic dose in humans of $\gamma-$

Copyright @ 2020: This is an open-access article distributed under the terms of the Creative Commons Attribution license which permits unrestricted use, distribution, and reproduction in any medium for non commercial use (NonCommercial, or CC-BY-NC) provided the original author and source are credited. 
$\mathrm{HCH}$ can lead to blood and central nervous system disorders. Oral intake of a substantial quantity of $\gamma$-HCH has resulted in seizures and death in some cases [8].

The use of OCPs has been limited in many countries [9] based on Stockholm Convention of Persistent Organic Pollutants [10] and restricted in about thirty-three countries [11]. Their restrictive use made them to be classified as prescription medicine in the form of lotions, creams, or shampoos to manage and treat scabies and lice in humans. However, in some developing countries, they are unscrupulously used in food preservation [12].

Various columns have been used in the analysis of DDT and $\gamma-\mathrm{HCH}$ in cowpeas [13, 14]. However the use of Restek column has the special selectivity for analysing OCPs, reduced time of run. Its also differentiate time of retention and elution orders for confirmatory analysis irrespective of the mobile phase. It has the advantage of meeting the criteria set by U.S. EPA and other method criteria.

Cowpea (Vigna unguiculata (L.) Walp.) is a widely grown legume and native to West and Central Africa, but also cultivated in other parts of the world [15]. It is a staple food in South-West states of Nigeria, with high population density [16]. OCPs are often added by marchant to cowpeas to prevent it attack by weevils during storage. The level of these OCPs have been shown to exceed maximum residual limit MRL set by the EU in some markets in Osun and Oyo state, but there is paucity of information with respect to several other markets in the South-West. Thus, the objective of this study was to determine the concentration of DDT and $\gamma$-lindane in cowpea collected from South-West states, determine their daily intake in this area and subsequently compare the concentrations obtained with maximum residual limits set by appropriate regulartory authority.

\section{MATERIALS AND Methods}

\section{Studied area and collection of samples}

Cowpeas were obtained from wholesale markets or outlets in South-West states-Ekiti state (Agbado, Isinbodi and Oja oba), Lagos state (Agege, Iddo, Ile Epo and Oja Oba), Ogun state (Siun, Okitipupa, Ibaka), Ondo (Ibeno, Ile Epo, Ijebu), Oyo state (Eleyele, Iwo Road, Bodija) and Osun state (Ife, Ede, Osogbo). Cowpeas were collected at random from these markets and placed in a polyethene zip-lock bags before it was taken to the University of Benin Pesticide Research Laboratory (UBPRL) and immediately placed in the refrigerator at a temperature of $4^{\circ} \mathrm{C}$ until analyzed.

\section{Reagents and Chemicals}

Analytical grade chemicals and reagents were used in this study. Anhydrous sodium sulphate was purchased from Labscan, silica gel was obtained from Oxford laboratory (India). Analytical grade dichloromethane and acetone were supplied by Sigma-Aldrich, USA. Distilled water was obtained from in-house purification system while DDT and $\gamma$-HCH reference standards were purchased from Sigma-Aldrich, South Africa.

\section{Extraction, clean-up and quantification of cowpea}

Hand-picked cowpeas seeds (10 g) were reduced to fine powder by milling machine (Victoria), extracted with Soxhlet apparatus containing $150 \mathrm{ml}$ of dichloromethane at $60{ }^{\circ} \mathrm{C}$ for 180 minutes. Rotary evaporator at $40{ }^{\circ} \mathrm{C}$ was used to concentrate the extract to $5 \mathrm{ml}$ [14]. Column (15 cm x $9 \mathrm{~mm}$ I.D) packed with $7 \mathrm{~g}$ of silica gel (160-200 mesh size) and $1 \mathrm{~g}$ of anhydrous sodium sulphate was used for clean-up. The sample extract was loaded onto silica and eluted with $2 \mathrm{x} 10$ $\mathrm{ml}$ dichloromethane. The eluent was concentrated and reconstituted to $1 \mathrm{ml}$ in dichloromethane for GC-MS analysis. Reagent blanks were also analysed concurrently with the experimental cowpea.

Detection and quantitation of the DDT and $\gamma-\mathrm{HCH}$ were done by an external standard method, by using GCMS-QP 2010 SE Shimadzu, (JAPAN). The Gas Chromatography (GC) was equipped with an electron capture detector which used for identification analysis of the DDT and $\gamma-\mathrm{HCH}$ based on the retention values. The column used was a Restek Stx -CL column of length, internal and thickness ( $30 \mathrm{~m}, 0.32 \mathrm{~mm}$ and $0.5 \mu \mathrm{m})$.

GC conditions: the GC was operated in the splitless injection mode with helium (carrier gas) flow rate was 1 $\mathrm{ml} / \mathrm{min}$. The injection temperature maintained at $250^{\circ} \mathrm{C}$, while the volume injected was $8 \mu \mathrm{l}$. The programmed column temperatures were: $120{ }^{\circ} \mathrm{C}(0: 00 \mathrm{~min})$, to 200 at $45^{\circ} \mathrm{C} \min ^{-1}(0: 00 \mathrm{~min})$ to $230{ }^{\circ} \mathrm{C}$ at $12.5^{\circ} \mathrm{C} \min ^{-1}$, at $325^{\circ} \mathrm{C}$ it was held for $2 \mathrm{~min}$, at $30^{\circ} \mathrm{C} \mathrm{min}-{ }^{1}$. Samples were injected automatically by split-less mode into the MS at an interface temperature of $250^{\circ} \mathrm{C}$ with ion source at $230^{\circ} \mathrm{C}$ with ionization mode of election impact ionization (EI) of $70 \mathrm{eV}$. For the quantification analysis, selected ion monitoring was maintained with emphasis on two specific ions for quantification and confirmation. Retention time and abundance of the confirmation ions relative to that of quantification ion were used as identification criteria. Quality assurance and control were done by conducting the linearity, precision and recovery experiments for DDT and $\gamma-\mathrm{HCH}$. 
The recovery, precision and linearity of DDT and $\gamma-\mathrm{HCH}$ were determined by adding $1 \mathrm{ml}$ of a working mixture in dichloromethane to $10 \mathrm{~g}$ of pulverised cowpea; spiked samples stood for $24 \mathrm{hrs}$ to ensure complete evaporation of the solvent after proper mixing of the matrices before extraction and analysis. Daily repeatability of five samples gave the precision, while reproducibility was done on three different days. Three replicate samples were used for the recovery experiment. Spiked samples gave a percentage range from 84 to $98 \%$. Accordingly, the sample analysis data were corrected for these recoveries. Limit of quantitation (LOQ) for this method was evaluated based on the minimum concentrations of residues in each of the matrices that were repeatedly measured at the GC-MS operating conditions; DDT and $\gamma-\mathrm{HCH}$ have a value of $0.01 \mathrm{mg} / \mathrm{kg}$. Interference from the reagents was checked by carrying out a blank and spike analysis on every batch of the sample. Selected ion monitoring (SIM) mode was used in the GC-MS analysis of all the samples.

\section{Statistical Data Analysis}

Instat graph pad was used to evaluate and test the peak area for each analyte obtained from the GC-MS analysis. Calibration graph formula was used to determine the concentration of each unknown analyte by interfering the integrated peak area. P-values were considered to be significantly different at $<0.05,<0.01,<0.001$ among repetitive tests ( $\mathrm{n}=4$ ).

\section{Results}

Tables-1 shows the mean concentrations of DDT and $\gamma-\mathrm{HCH}$ in cowpeas collected from the markets in this region, expressed as mean \pm SEM. DDT was detected in fifteen out of nineteen markets while $\gamma$-HCH was detected in sixteen markets out of nineteen markets. The markets where DDT was not detected include Ibaka (Ondo state), Ile Epo (Lagos state), Ife and Ede (Osun state) markets while $\gamma-\mathrm{HCH}$ was not detected in Ife, Ede and Osogbo market in Osun state.

The range of concentration is from trace to $(11.42 \pm 0.242) \mu \mathrm{g} / \mathrm{kg}$ and trace to $(168.00 \pm 0.114) \mu \mathrm{g} / \mathrm{kg}$ for DDT and $\gamma-\mathrm{HCH}$ respectively. The level of DDT was highest in Eleyele market in Oyo state but was below the MRL set by WHO while Agege $(168.00 \pm 0.114) \mu \mathrm{g} / \mathrm{kg}$, Iddo $(63.140 \pm 0.178) \mu \mathrm{g} / \mathrm{kg}$ and Eleyele $(64.26 \pm 0.138) \mu \mathrm{g} / \mathrm{kg} \mathrm{markets}$ had high levels of $\gamma-\mathrm{HCH}$ in Lagos state and were above the set standard and may an indication of indiscriminate usage in SouthWest.

Figure-1 gave a picture of the presence of DDT and $\gamma-\mathrm{HCH}$ in the same cowpeas sample collected from some markets. A significant difference in variation of the mean concentration of $\gamma-\mathrm{HCH}(\mathrm{P}=0.001)$ between Bodija and Iwo road markets and between the Eleyele and Iwo road markets located in Oyo state were observed. A similar observation was also seen in Ondo state $(\mathrm{P}=0.001)$.

Calibration graphs for DDT and $\gamma-\mathrm{HCH}$ were done within the ranges of $0.50-3.00 \mu \mathrm{g} / \mathrm{ml}$ with a correlation coefficient of 0.9984 and 0.9980 respectively. Table-2 shows the maximum residual limits (MRL), linear regression, correlation coefficients, LOD, LOQ and \% RSD. LOD for DDT and $\gamma-\mathrm{HCH}$ are 0.05 and $0.06 \mu \mathrm{g} / \mathrm{ml}$ while LOQ are 0.15 and $0.18 \mu \mathrm{g} / \mathrm{ml}$. The \% RSD percentage of migration time value are $7.00 \%$ and $4.5 \%$ for DDT and $\gamma-\mathrm{HCH}$, showing method repeatability. Recovery efficiencies were investigated by analysing pesticides free cowpea samples spiked with DDT and $\gamma-\mathrm{HCH}$ standards $(\mathrm{n}=5)$. Matrix effects and procedural performance were determined by the introduction of standard (surrogate) in the samples. Surrogate spikes recoveries in samples vary from $84 \%$ to $98 \%$ as shown in Table-2.

Table-4 shows the Health risk estimate for DDT and $\gamma-\mathrm{HCH}$ residue in cowpeas. The second column represents the accepted daily intake for DDT and $\gamma-\mathrm{HCH}$. The third column is the estimated daily intake for DDT and $\gamma-\mathrm{HCH}$. The fourth column represents the health index for DDT and $\gamma-\mathrm{HCH}$ and it is expected to be less than $1(<1)$ for the food item to be considered fit for consumption. Column five gives the health risk for DDT and $\gamma-\mathrm{HCH}$, detected in this study

Table-1: Mean concentration of DDT and $\gamma-\mathrm{HCH}$ in cowpea collected from markets in South-West states of Nigeria expressed as Mean \pm SEM

\begin{tabular}{|l|l|l|l|}
\hline S/N & States/Towns & Weight of $\boldsymbol{\gamma}-\mathbf{H C H}(\boldsymbol{\mu g} / \mathbf{k g})$ & DDT in cowpea $(\boldsymbol{\mu g} / \mathbf{k g})$ \\
\hline $\mathbf{1}$ & OSUN & & \\
\hline & Ife & ND & ND \\
\hline & Ede & ND & ND \\
\hline & Osogbo & ND & $2.67 \pm 0.154$ \\
\hline $\mathbf{2}$ & LAGOS & & \\
\hline & Agege & $168.00 \pm 0.114$ & $4.662 \pm 0.146$ \\
\hline & Iddo & $63.140 \pm 0.178$ & $2.98 \pm 0.145$ \\
\hline & Ile Epo & $0.022 \pm 0.00432$ & ND \\
\hline & Oja Oba & $0.018 \pm 0.00316$ & $5.20 \pm 0.101$ \\
\hline
\end{tabular}


Emmanuel Eimiomodebheki Odion et al.; South Asian Res J Agri Fish; Vol-2, Iss-3 (May-June, 2020): 79-84

\begin{tabular}{|l|l|l|l|}
\hline $\mathbf{3}$ & OYO & & \\
\hline & Eleyele & $64.26 \pm 0.138$ & $11.42 \pm 0.242$ \\
\hline & Iwo Road & $0.01350 \pm 0.00222$ & $10.39 \pm 0.287$ \\
\hline & Bodija & $0.03550 \pm 0.00206$ & $6.537 \pm 0.523$ \\
\hline $\mathbf{4}$ & EKITI & & \\
\hline & Oja Oba & $2.567 \pm 0.019$ & $0.0340 \pm 0.0301$ \\
\hline & Isinbodi & $2.800 \pm 0.0277$ & $0.0490 \pm 0.0142$ \\
\hline & Agbado & $1.876 \pm 0.0168$ & $0.0940 \pm 0.0388$ \\
\hline $\mathbf{5}$ & ONDO & & \\
\hline & Siun & $0.5535 \pm 0.00933$ & $0.0640 \pm 0.0208$ \\
\hline & Okitipupa & $0.1100 \pm 0.00203$ & $0.0970 \pm 0.0258$ \\
\hline & Ibaka & $0.10710 \pm 0.00470$ & ND \\
\hline $\mathbf{6}$ & OGUN & & \\
\hline & Ibeno & $1.334 \pm 0.0335$ & $0.1205 \pm 0.0392$ \\
\hline & Ile Epo & $0.863 \pm 0.0125$ & $0.1445 \pm 0.0575$ \\
\hline & Ijebu & $0.777 \pm 0.0157$ & $0.0955 \pm 0.0130$ \\
\hline & & \multicolumn{1}{c}{ ND $=$ Not detected } \\
\hline
\end{tabular}

Table-2: The linear regression $(y=a x+b)$, correlation coefficients $\left(R^{2}\right), \operatorname{LOD}(\mu \mathrm{g} L-1), \operatorname{LOQ}\left(\mu \mathrm{g} \mathrm{L}^{1}\right)$, MRL $(\mu \mathrm{g}$ $\left.\mathrm{kg}^{-1}\right)$ and \% RSD of the method

\begin{tabular}{|l|l|l|l|l|l|l|l|}
\hline Pesticide & $\mathbf{y}=\mathbf{a x}+\mathbf{b}$ & $\mathbf{R}^{\mathbf{2}}$ & LOD & LOQ & Recovery (\%) & MRL & \%RSD \\
\hline DDT & $365951 \mathrm{x}-10706$ & 0.9984 & 0.05 & 0.15 & 84 & 50 & 7.0 \\
\hline $\boldsymbol{\gamma}$-HCH & $26890 \mathrm{x}-11343$ & 0.9980 & 0.06 & 0.18 & 98 & 20 & 4.5 \\
\hline
\end{tabular}

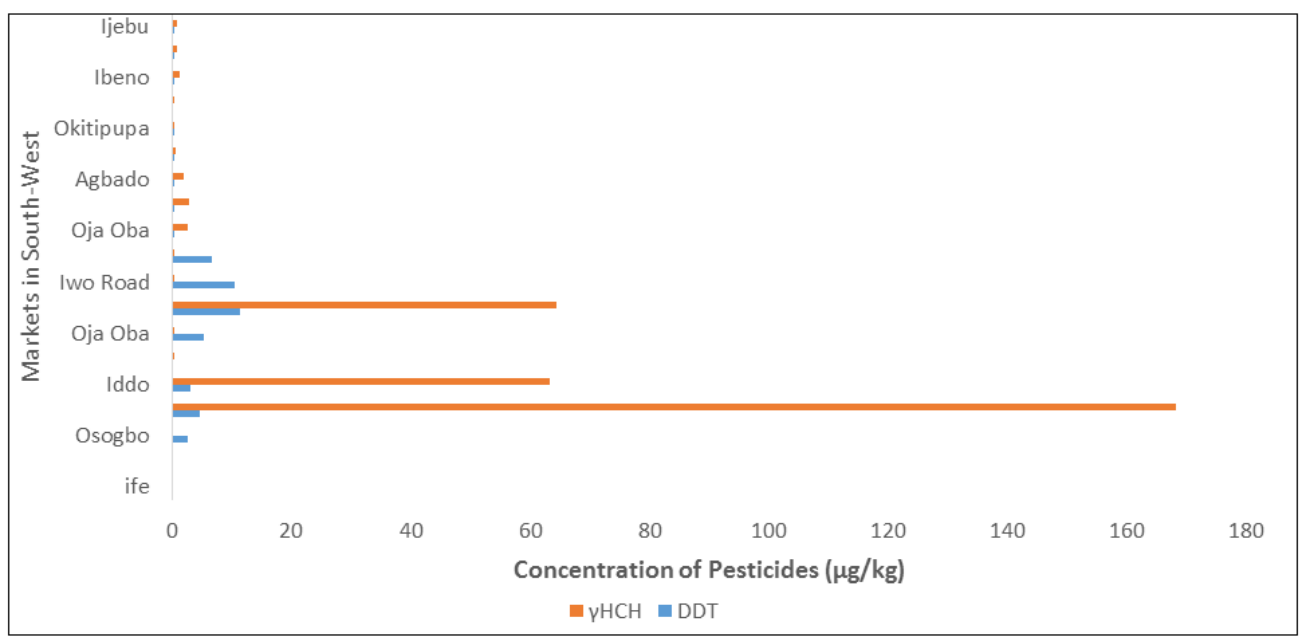

Fig-1: Mean concentration of DDT and $\gamma-\mathrm{HCH}$ in the various markets in South-West of Nigeria

Table-3: SIM conditions of DDT and $\gamma$-HCH detected by GC-MS

\begin{tabular}{|l|l|l|l|l|l|}
\hline Pesticide & $\mathbf{t}_{\mathbf{R}}(\mathbf{m i n})$. & Molecular weight & Quantitationion & Confirmationions 1 & Confirmationion 2 \\
\hline DDT & 6.20 & 352 & 235 & 165 & 237 \\
\hline $\boldsymbol{\gamma}$-HCH & 4.36 & 288 & 181 & 183 & 219 \\
\hline
\end{tabular}

Table-4: Health risk estimate for DDT and $\gamma$-HCH residue in Cowpeaobtained from South-West of Nigeria

\begin{tabular}{|l|l|l|l|l|}
\hline Pesticide & ADI $\mathbf{~ m g / k g / d a y ~}$ & EADI mg/kg/day & Health index & Health risk \\
\hline DDT & 0.0200 & $196.148 \times 10^{-6}$ (Adult) & 0.0098074 & No \\
& & $1373.036 \times 10^{-6}$ (Children) & 0.0686518 & No \\
\hline $\boldsymbol{\gamma}$-HCH & 0.0003 & $262.5147 \times 10^{-6}$ (Adult) & 0.875049 & No \\
& & $1837.603 \times 10^{-6}$ (Children) & 6.12534333 & Yes \\
\hline
\end{tabular}

\section{DISCUSSION}

From the results of the experiment, DDT and $\gamma-\mathrm{HCH}$ were detected in cowpeas from the south-west of Nigeria and are known OCPs that are effective against their target vectors [17]. Their use has been restricted or banned in most countries but it is still been produced [18], hence they may be detected in food as a result of illicit use and environmental persistence of these chemicals. One of the properties of DDT includes lipophilicity, which makes it readily bind with 
fatty tissue at low concentrations when ingested and due to its chemical stability, it concentrates and accumulates in the body [19]. Its presence in the body could affect the nervous system through the alternation and disruption of the crossing of ions in and out of nerve cells, resulting in endogenous changes, embryos deformation and eggshell thinning in birds [20,21]. DDT and $\gamma-\mathrm{HCH}$ exposures have led to suppression or induction of several immune parameters [22], increased mortality from pancreatic cancer and diabetes [23]. Their detection in cowpeas revealed that they may have been added during storage or became contaminated from the farm as a result of an application to kill insects during the pre-harvest season. DDT are classified as persistent organic pollutant (POP), reducing the need for regular use, and can be moved by both water and air currents from the point of application.

A mixture of pesticides has been detected in food [24] and toxicological study has shown that in-vivo exposures to two or more pesticides could result in synergy or additive effect, inhibiting enzymes in part of the central nervous system of some growing fish. An additive effect of DDT and $\gamma-\mathrm{HCH}$ which possess a different mechanism of action could lead to both hormonal disruption and central nervous system excitation taking place simultaneously. In some cases, the doses of DDT and $\gamma-\mathrm{HCH}$ detected were mostly low, but their presence in a single cowpea sample is undesirable to the health of the consumer.

\section{CONCLUSION}

This study has shown that a regularly consumed food item (cowpeas) which contains DDT and/or $\gamma$-HCH may be unfit for human consumption. The need for the regulatory authorities to conduct regular checks on cowpeas for pesticides cannot be over-emphasised. Workshops to sensitize farmers and merchants on the consequent health implications of using DDT and $\gamma-\mathrm{HCH}$ to preserve cowpeas and the importance of using appropriate storage chemicals and facilities of cowpeas should be advocated. Further study should be carried out with emphasis on the decontamination process of cowpea laden with pesticides.

\section{Funding}

This study was funded by the national tertiary education trust fund (TEFUND/NRF2014) of the Federal Government of Nigeria.

Author's Contributions: This is an aspect of the corresponding author PhD thesis, while the others are supervisors.

Conflicts of Interests: There is no conflict of interest between the authors and with any other agencyonthe said work.

\section{ACKNOWLEDGEMENTS}

Special thanks to Tertiary Education Trust Fund for the grant which supported this work. (TETFUND/NRF2014 'Use of pesticides in food preservation in Nigeria and its implications').

\section{REFERENCES}

1. Jayaraj, R., Megha, P., \& Sreedev, P. (2016). Organochlorine pesticides, their toxic effects on living organisms and their fate in the environment. Interdisciplinary toxicology, 9(3-4), 90-100.

2. Guillette Jr, L. J. (2006). Endocrine disrupting contaminants-beyond the dogma. Environmental health perspectives, 114(Suppl 1), 9-12.

3. Kelce, W. R., Stone, C. R., Laws, S. C., Gray, L. E., Kemppainen, J. A., \& Wilson, E. M. (1995). Persistent DDT metabolite p, p'-DDE is a potent androgen receptor antagonist. Nature, 375(6532), 581-585.

4. ATSDR. (1997). Toxicological Profile for Alpha-, Beta-, Gamma-, and Delta- Hexachlorocyclohexane. Draft for Public Comment. U.S. Public Health Service, U.S. Department of Health and Human Services, Atlanta, GA.

5. Stehr- Green, P. A. (1989). Demographic and seasonal influences on human serum pesticide residue levels. Journal of Toxicology and Environmental Health, Part A Current Issues, 27(4), 405-421.

6. Vijgen, J., Abhilash, P. C., Li, Y. F., Lal, R., Forter, M., Torres, J., ... \& Weber, R. (2011). Hexachlorocyclohexane $(\mathrm{HCH})$ as new Stockholm Convention POPs - a global perspective on the management of Lindane and its waste isomers. Environmental Science and Pollution Research, 18(2), 152-162.

7. Smith, A. G. (1991). Chlorinated Hydrocarbon Insecticides. in Handbook of Pesticide Toxicology, Volume 3, Classes of Pesticides. Wayland J. Hayes Jr. and Edward R. Laws, Jr. editors. Academic Press, Inc., NY.

8. Wiles, D. A., Russell, J. L., Olson, K. R., Walson, P. D., \& Kelley, M. (2015). Massive lindane overdose with toxicokinetics analysis. Journal of Medical Toxicology, 11(1), 106-109.

9. Hester, R. E., \& Harrison, R. M. (Eds.). (1996). Chlorinated organic micropollutants (Vol. 6). Royal Society of Chemistry. 
10. United Nations Environment Programme (cited 2007 Nov). Future Plans for Work on DDT Elimination. A Stockholm Convention Secretariat Position Paper. Geneva: Secretariat of the Stockholm Convention, Available from https:// chm.pops.int/Portals/0/Repository/DDT-general/UNEP-POPS-DDT PROPSSCPP.English.PDF

11. Humphreys, E. H., Janssen, S., Heil, A., Hiatt, P., Solomon, G., \& Miller, M. D. (2008). Outcomes of the California ban on pharmaceutical lindane: Clinical and ecologic impacts. Environmental health perspectives, 116(3), $297-302$.

12. Prato, M., Polimeni, M., \& Giribaldi, G. (2013). DDT as anti-malaria tool: the bull in the China shop or the elephant in the room?. Insecticides-Development of Safer and More Effective Technologies.

13. Sosan, M. B., Oyekunle, J. A. O., \& Olufade, Y. A. (2015). Dichloro-diphenyl-trichloro-ethane (DDT) and hexachlorohexane $(\mathrm{HCH})$ pesticide residues in foodstuffs from markets in Ile-Ife, Nigeria. International Journal of Biological and Chemical Sciences, 9(1), 442-453.

14. Olufade, Y. A., Sosan, M. B., \& Oyekunle, J. A. O. (2014). Levels of organochlorine insecticide residues in cowpea grains and dried yam chips from markets in Ile-Ife, Southwestern Nigeria: a preliminary survey. Ife Journal of Science, 16(2), 161-170.

15. Njonjo, M. W., Muthomi, J. W., \& Mwang'ombe, A. W. (2019). Production Practices, Postharvest Handling, and Quality of Cowpea Seed Used by Farmers in Makueni and Taita Taveta Counties in Kenya. International Journal of Agronomy, 2019:1-12.

16. Report of Nigeria's National Population Commission on the 2006 Census Population and Development Review. 2006;33, 1. 206-210

17. United Nations Environment Programme. (2005). Ridding the World of Pops: A Guide to the Stockholm Convention on Persistent Organic Pollutants. Secretariat of the Stockholm Convention on Persistent Organic Pollutants United Nations Environment Programme (UNEP) Chemicals.

18. Van Den Berg, H., Manuweera, G., \& Konradsen, F. (2017). Global trends in the production and use of DDT for control of malaria and other vector-borne diseases. Malaria journal, 16(1), 401.

19. Waliszewski*, S. M., Gómez-Arroyo, S., Infanzón, R. M., Carvajal, O., Villalobos-Pietrini, R., Trujillo, P., \& Maxwell, M. (2004). Persistent organochlorine pesticide levels in bovine fat from Mexico. Food additives and contaminants, 21(8), 774-780.

20. Ratcliffe, D. A. (1970). Changes attributable to pesticides in egg breakage frequency and eggshell thickness in some British birds. Journal of Applied Ecology, 67-115.

21. Tesfahunegny, W. (2016). Impact of pesticides on birds from DDT to current fatality: a literature review. Journal of Zoology Studies, 3(2), 44-55.

22. Daniel, V., Huber, W., Bauer, K., Suesal, C., Conradt, C., \& Opelz, G. (2002). Associations of dichlorodiphenyltrichloroethane (DDT) 4.4 and dichlorodiphenyldichloroethylene (DDE) 4.4 blood levels with plasma IL-4. Archives of Environmental Health: An International Journal, 57(6), 541-547.

23. Beard, J., \& Australian Rural Health Research Collaboration. (2006). DDT and human health. Science of the total environment, 355(1-3), 78-89.

24. Kovac, I. (2014). Quantification of organochlorine pesticides in selected food samples byGC/ECD. Congress of Chemists and Chemical Engineers of BIH. 